\title{
Submicromolar copper (II) ions stimulate transretinal signaling in the isolated retina from wild type but not from Cav2.3-deficient mice
}

Toni Schneider ( $\boldsymbol{\nabla}$ toni.schneider@uni-koeln.de)

Institute of Neurophysiology, and Center for Molecular Medicine Cologne (CMMC)

https://orcid.org/0000-0003-2816-2696

Jan Niklas Lüke

University of Cologne, Institute of Neurophysiology

Felix Neumaier

University of Cologne, Institute of Neurophysiology

\section{Serdar Alpdogan}

University of Cologne, Institute of Neurophysiology

Jürgen Hescheler

University of Cologne, Institute of Neurophysiology

Walid Albanna

Rheinisch-Westfalische Technische Hochschule Aachen, Department of Neurosurgery

\section{Isha Akhtar-Schäfer}

University of Cologne, Institute of Neurophysiology

\section{Research article}

Keywords: Murine ERG; isolated vertebrate retina; b-wave; reverse inhibition.

Posted Date: February 20th, 2020

DOI: https://doi.org/10.21203/rs.2.16907/v2

License: (c) (i) This work is licensed under a Creative Commons Attribution 4.0 International License.

Read Full License

Version of Record: A version of this preprint was published at BMC Ophthalmology on May 6th, 2020. See the published version at https://doi.org/10.1186/s12886-020-01451-8. 


\section{Abstract}

Background : So far, only indirect evidence exists for the pharmacoresistant R-type voltage-gated Ca 2+ channel (VGCC) to be involved in transretinal signaling by triggering GABA-release onto ON-bipolar neurons. This release of inhibitory neurotransmitters was deduced from the sensitivity of the b-wave to stimulation by $\mathrm{Ni} 2+, \mathrm{Zn} \mathrm{2+}$ and $\mathrm{Cu} 2+$. To further confirm the interpretation of these findings, we compared the effects of $\mathrm{Cu} 2+$ application and chelation (using kainic acid, KA) on the neural retina from wild type and Ca v 2.3-deficient mice. Furthermore, the immediately effect of KA on the ERG b-wave modulation was assessed. Methods : Transretinal signaling was recorded as an ERG from the superfused murine retina isolated from wildtype and Ca $\vee 2$.3-deficient mice Results : In mice, the stimulating effect of $100 \mathrm{nM} \mathrm{CuCl} 2$ is absent in the retinae from Ca v 2.3-deficient mice, but prominent in Ca v 2.3competent mice. Application of up to $3 \mathrm{mM}$ tricine does not affect the murine b-wave in both genotypes, most likely because of chelating amino acids present in the murine nutrient solution. Application of 27 $\mu \mathrm{M}$ KA significantly increased the b-wave amplitude in wild type and Ca $\vee 2.3(-1-)$ mice. This effect can most likely be explained by the stimulation of endogenous KA-receptors described in horizontal, OFFbipolar, amacrine or ganglion cells, which could not be fully blocked in the present study. Conclusion: $\mathrm{Cu}$ $2+$ dependent modulation of transretinal signaling only occurs in the murine retina from Ca $v 2.3$ competent mice, supporting the ideas derived from previous work in the bovine retina that R-type $\mathrm{Ca} 2+$ channels are involved in shaping transretinal responses during light perception.

\section{Background}

Copper-, iron-, and zinc-ions are essential in human biochemical function. Their concentration in vivo is under tight control, and a dyshomeostasis may cause electrical imbalance and consecutively, regionselective neurodegeneration eventually facilitating cognitive deficits. In a systematic quantification of all three biometals in the human brain, age-associated changes in the elderly population were quantified in postmortem neocortical tissue. While $\mathrm{Zn}^{2+}$ was unaffected in any disease pathologies of the brain, both $\mathrm{Cu}^{2+}$ and $\mathrm{Fe}^{3+}$ showed a gradual age-associated decline in healthy non-cognitively impaired individuals. Further, $\mathrm{Cu}^{2+}$ was significantly reduced by $20 \%$, and Fe ${ }^{2+}$ significantly increased by $10-16 \%$ in severe Alzheimer disease (AD) compared with age-matched controls [1].

Various ion channels were reported to be highly sensitive towards $\mathrm{Zn}^{2+}$ and $\mathrm{Cu}^{2+}$ at concentrations below $10 \mu \mathrm{M}$ (summarized in [2, 3]). Among them are glutamate-, glycine-, GABA-A-, acetylcholine- and P2Xreceptors as well as voltage-gated $\mathrm{Na}^{+}\left(\mathrm{Na}_{\mathrm{v}} 1.5\right), \mathrm{K}^{+}(\mathrm{K} 2 \mathrm{P}, \mathrm{Kv} 1.3, \mathrm{mSlo} 1)$, and $\mathrm{Ca}^{2+}\left(\mathrm{Ca}_{\mathrm{v}} 3.2\right)$ channels [4-6].

Polyvalent inorganic cations can interfere with the function of VGCCs through various mechanisms, which include electrostatic effects, pore block, and in some cases allosteric effects [3]. Besides, endogenous $\mathrm{Zn}^{2+}$ and $\mathrm{Cu}^{2+}$ are increasingly recognized to be involved in central neurotransmission, although their exact role remains ambiguous. Both can be released spontaneously or in an activationdependent manner from defined populations of neurons located primarily in limbic regions (hippocampus, amygdala) in the cerebral cortex and in the retina [7] (for a summary see [8]). 
The isolated and superfused vertebrate retina represents an important model of a neuronal network for the functional investigation of postsynaptic excitation conduction [9-11]. Using the bovine retina, the process of reciprocal inhibition during transretinal signaling was investigated in detail $[8,12,13] . \mathrm{Cu}^{2+}$ occupy an allosteric binding site on the domain I gating module of $\mathrm{Ca}_{\mathrm{v}} 2.3$ channels and may interfere with voltage-dependent-gating. Several studies have shown that even very nominal $\mathrm{Cu}^{2+}$ concentrations are sufficient for significant suppression of these channels, as electroretinographically demonstrated on the ex-vivo bovine retina [14]. It was found that L-Glutamate, as excitatory amino acids, can stimulate $\mathrm{Ca}_{\mathrm{v}}$ 2.3-channels by being as trace metal chelators and inhibiting the suppressing effects of metal ions such as $\mathrm{Zn}^{2+}$ and $\mathrm{Cu}^{2+}[15]$. The naturally occurring excitatory amino acid Kainic acid has an embedded L-glutamic acid unit, and thus, a potent agonist at (non-NMDA) glutamate receptors. The systemic application produces epilepsy in rodent experiments [16] and in this context, $\mathrm{Ca}_{\mathrm{v}} 2.3$ channels can act to the pathogenesis of KA-induced seizures $[17,18]$. However, the structural similarity of kainic acid to LGlutamate led us to investigate the chelating effect in the presence of physiologically concentrations of $\mathrm{Cu}^{2+}$.

To understand molecular mechanisms of the biometals, this technique of the isolated and superfused retina was successfully transferred to the isolated mouse retina from control and $\mathrm{Ca}_{\mathrm{v}} 2$.3-deficient mice $[19,20]$. Those recordings of a full electroretinogram (ERG) from the isolated and superfused murine retina were optimized only recently [11] by modifying the composition of the standard Ames solution [21]. After gentle isolation of the retina, the development of the b-wave, indicative for transretinal signaling, was stabilized by adding barium chloride $(0.1 \mathrm{mM})$ to the final perfusion solution, similar as it was reported originally for eyecup preparations of the tiger salamander [22].

In the present report, recordings of the full ERG were possible and were compared between the $\mathrm{Ca}_{\mathrm{v}} 2.3$ competent and the -deficient mouse retina to understand if $\mathrm{Ca}_{\mathrm{v}} 2.3$ is involved in transretinal signaling as supposed from recordings in the bovine retina.

\section{Methods}

\subsection{Materials}

Glucose and the constituents of the nutrient solution used for retinal superfusion were purchased from Merck (p.a. grade). For the preparation of the murine retina [11] a superfine scissor (WPI, Nr. 501839), and an ultrafine suturing forceps (WPI, Nr. 555063FT) were used. Further, a 27-gauge needle (Sterican, size 20: $0.4 \mathrm{~mm} \times 20 \mathrm{~mm} \mathrm{BI} / \mathrm{LB}$ ) was used to punch a hole into the cornea of the extirpated eye bulb. The receptor antagonists UBP 301 and CNQX were purchased from Sigma Aldrich (Munich, Germany).

\subsection{Animals}

In order to compare ERG responses from mice deficient of the voltage-gated $\mathrm{Ca}^{2+}$-channel $\mathrm{Ca}_{\mathrm{v}} 2.3$ (R-type), we used control mice with an identical genetic background. Both mouse lines were generated and bred in 
our animal facility. $\mathrm{Ca}_{\mathrm{v}} 2$.3-deficient animals and control mice were kept as separate mouse lines derived from heterozygous parents (fourth backcrossing into C57BI/6). Homozygous littermates were regularly interbred with each other and back-bred into $\mathrm{C} 57 \mathrm{BI} / 6$ (for further information on $\mathrm{Ca}_{\mathrm{v}}$ 2.3-deficient generation see $[23,24])$. In short, the cacna1e gene encoding $\mathrm{Ca}_{\mathrm{v}} 2.3$ was disrupted in vivo by agouticolored $\mathrm{Ca}_{\mathrm{v}} 2.3(\mathrm{fl} \mid+)$ and deleter mice expressing Cre-recombinase constitutively [25]. Thus, exon 2 was ablated by Cre-mediated recombination. $\mathrm{Ca}_{\mathrm{v}}$ 2.3-deficient mice were fertile, exhibited no obvious behavioral abnormalities and had the same lifespan as control mice. The Cav2.3-deficient mouse line, which was generated in the Cologne lab was transferred to the Mutant Mouse Resource \& Research

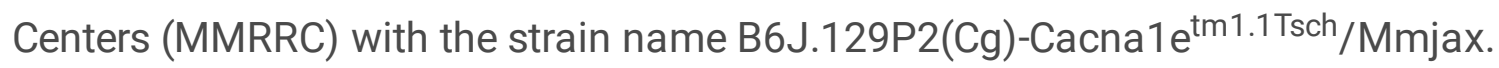

Adult male mice were used at the age of 12 to 18 month and kept at 20 to $22^{\circ} \mathrm{C}$ in makrolon type II cages under a 12h light-dark cycle (7:00 a.m./p.m.) with food and water provided ad libitum. All animal experiments were in line with the European Communities Council Directive 2010/63/EU for the care and use of laboratory animals as described in the UFAW handbook on the care and management of laboratory animals. All experiments were approved by the local institutional committee on animal care (UniKöln_Anzeige§4.17.007).

\subsection{Methods}

In order to reach maximum transretinal signaling realized by a full ERG, the bovine [10] and the murine retina [11] had to be superfused under different conditions (Tab. 1).

Bovine eyes were received from a local slaughterhouse and immediately stored in a nutrient solution (Sickel medium), which was aerated with pure oxygen, consisting of the following (in $\mathrm{mM}$ ): $\mathrm{NaCl}(120)$, $\mathrm{KCl}$ (2.0), $\mathrm{CaCl}_{2}$ (0.15), $\mathrm{MgCl}_{2}$ (0.1), $\mathrm{NaH}_{2} \mathrm{PO}_{4}$ (1.5), $\mathrm{Na}_{2} \mathrm{HPO}_{4}$ (13.5) and glucose (5) with a final pH of 7.8. The bovine retina was isolated as described in detail by Luke et al. 2005 [10]. After isolation, a plain retina segment was transferred into the recording chamber described below, which is placed in an electrically and optically isolated air thermostat. From the dark-adapted retina and in response to a single white flash, electroretinograms were recorded at intervals of 5 minutes at $30^{\circ} \mathrm{C}$, with a constant superfusion at $1 \mathrm{ml} / \mathrm{min}$ controlled by a roll pump. The flash intensity was set to $6.3 \mathrm{mlux}$, with the duration of light stimulation at $500 \mathrm{~ms}$ [10].

After reaching a stable equilibrium of the light-evoked ERG responses, $5 \mathrm{mM}$ tricine (tricine, Sigma \# RES3077T-A701X) was added to the nutrient solution with $10 \mathrm{mM}$ (HEPES) (Carl Roth, p.A., \# H3375) and superfused for $30 \mathrm{~min}$. Washout was started thereafter with Sickel medium.

Murine retinas were isolated from mice of our animal facility department, in which the light-dark regime was $12: 12 \mathrm{hr}$, and the light intensity between 5 and $10 \mathrm{~lx}$ at the surface of the animal cages.

DNA-containing tissue samples were collected from tail biopsies. DNA was extracted and used as template for genotyping. Transcripts of $\mathrm{Ca}_{\mathrm{v}} 2.3$ were detected by RT-PCR (RT, reverse transcriptase) using primers, which flanked the deleted exon 2 and exon 3 region [23]. In short, contaminating protein and RNA 
were enzymatically digested by protease and RNAse, respectively. For the PCR amplification of indicative $\mathrm{Ca}_{\mathrm{v}}$ 2.3 DNA-fragments, about $1 \mu \mathrm{g}$ DNA was introduced and amplified with the forward primer (B45Hilx1) 5'- AAA AAC AGC CGG GGA AAG CTT AT-3' and the reverse primer (a1eb45r) 5'-ctg ccc ttt ctt ctt gcc tga c3'. The sizes of DNA fragments expected are $1056 \mathrm{bp}$ for the WT and $86 \mathrm{bp}$ for the $\mathrm{Ca}_{\mathrm{v}} 2.3-\mathrm{KOs}$. PCRs for the genotyping were performed using a DNAEngine Peltier thermal cycler (BioRad, Germany) or a PTC200 Peltier thermal cycler (MJ Research, Biozym Diagnostik, Germany) with the initial denaturation $\left(94^{\circ} \mathrm{C}\right.$ for $10 \mathrm{~min}$ ) followed by 34 cycles (denaturation at $94^{\circ} \mathrm{C}$ for $60 \mathrm{sec}$, annealing at $60^{\circ} \mathrm{C}$ for $90 \mathrm{sec}$, extension at $72^{\circ} \mathrm{C} 4 \mathrm{~min}$ ) and final extension at $72^{\circ} \mathrm{C}$ for $10 \mathrm{~min}$. The PCR products were separated by agarose gel electrophoresis and fluorescent bands were detected on a Herolab UVT-28M transilluminator by UV irradiation ( $312 \mathrm{~nm}$ excitation wave length).

For $\mathrm{Ca}_{\mathrm{v}} 2.3$, mouse lines were used as separate inbred strains for $\mathrm{Ca}_{\mathrm{v}} 2.3(+\mid+)$ and $\mathrm{Ca}_{\mathrm{v}} 2.3(-\mathrm{I})$, each after the fourth backcrossing in $\mathrm{C} 57 \mathrm{BI} / 6$ mice.

The mice used for the retina isolation were dark adapted overnight, sacrificed by cervical dislocation under dim red light and the eyes were extirpated immediately. Enucleated eyes were protected from light and transferred into carbogen ( $95 \% \mathrm{O}_{2} / 5 \% \mathrm{CO}_{2}$ )-saturated modified Ames medium respectively [11]. The isolation of the murine retina was started immediately post mortem and carried out under dim red light. The complete retina was transferred to the recording chamber [26] and the electroretinogram was recorded via two silver/silver-chloride electrodes on either side of the isolated retina. The recording chamber containing the retina was placed in an electrically and optically isolated air thermostat. From the dark-adapted retina responses to a single white flash were recorded at intervals of 3 minutes at $27.5^{\circ} \mathrm{C}$ and with a constant superfusion at $2 \mathrm{ml} / \mathrm{min}$ controlled by a roller pump. The duration of light stimulation was $500 \mathrm{~ms}$, controlled by a timer operating a mechanical shutter system. The pre-stimulus delay was $380 \mathrm{~ms}$. Unless noted otherwise, the flash intensity was set to 63 mlux at the retinal surface using calibrated neutral density filters.

As soon as the isolated retina was placed into the recording chamber, it was equilibrated for about 60 min in modified Ames-solution ( $n=20$ ERGs) (Tab. 1). After reaching a stable equilibrium of the light-evoked ERG responses, $100 \mathrm{nM} \mathrm{CuCl}_{2}$ was added to the modified Ames-medium and superfused for $30 \mathrm{~min}$ ( $n=10$ ERGs). Washout was started thereafter with $\mathrm{Cu}^{2+}$-free modified Ames-medium. Each ERG response contains 239 data points.

The ERG was amplified and bandpass-limited between 0.3 and $300 \mathrm{~Hz}$ (PowerLab 8/35; Animal Bio Amp FE136, ADIntruments, Oxford, UK). Light flash, heating unit, fan and roller pump were automatically controlled by National-Instruments (BNC-2120; DASY-Lab V8.0). For each experiment, a new retina was transferred to the recording chamber. The retina was superfused with nutrient solution and stimulated repetitively until the responses had reached a stable level (usually after 60 minutes of perfusion). Switching from one solution to another was performed with a three-way valve to prevent disturbance of the experimental conditions. Experimental protocols for the isolation, storage and incubation of the 
vertebrate retina can markedly alter phototransduction and transretinal signaling [27]. To quantify such changes, we evaluated the $a$ - and $b$-wave amplitudes and their implicit times.

\subsection{Data analysis}

The b-wave amplitude was measured from the trough of the a-wave to the peak of the b-wave. After reaching the equilibrium, the initial b-wave amplitude was set to $100 \%$ (= Pre) resulting preferably illustration of ERGs after treatment with drugs as well as after washout. Quantitative normally distributed data are presented as mean \pm standard error of mean (SEM) and as percentage. Nonparametric tests are demonstrated as median [1. quartile - 3. quartile]. Two-sided, paired Student t-test was used for comparison of quantitative parameters in case of normal distribution. If not applicable, Wilcoxon test was used instead.

All analyses were performed with IBM ${ }^{\circledR}$ SPSS $^{\circledR}$ Statistics V22.0 (IBM, Chicago, Illinois, USA).

\section{Results}

\subsection{Trace metal chelation by tricine in the bovine and the murine retina}

The bovine retina was adapted to a phosphate buffered nutrient solution ("Sickel-medium"), which was aerated with pure oxygen and contained a reduced $\mathrm{Ca}^{2+}$ concentration to prevent precipitation of calciumphosphate (apatit).

As described in a previous publication, stable ERGs from the murine retina can be recorded in a carbonate buffered nutrient solution (AMES-medium), comprising additionally several amino acids. Further, the medium was slightly modified by adding $0.1 \mathrm{mM} \mathrm{BaCl}_{2}$ to avoid the M-wave causing a reduction of the apparent b-wave amplitude [22] and by shifting the $\mathrm{pH}$ to a more alkaline value (Tab. 1).

The ERG b-wave amplitude of the bovine retina is known to be reversibly reduced in the presence of $5 \mathrm{mM}$ tricine [28], which was shown to be caused by the chelation of trace metal cations as impurities in HEPES buffer or by chelation of $100 \mathrm{nM}$ added $\mathrm{CuCl}_{2}$. In the bovine retina, submicromolar $\mathrm{Cu}^{2+}[28]$ blocks the $\mathrm{Ca}_{\mathrm{v}}$ 2.3 R-type $\mathrm{Ca}^{2+}$ channel even more effectively than comparable $\mathrm{NiCl}_{2}$ [12] or $\mathrm{ZnCl}_{2}$ concentrations [8]. However, tricine did not change significantly the b-wave amplitude of the murine retina during successive application of $0.1,1$ and $3 \mathrm{mM}$ tricine in the superfusing solution (Fig. 1, n=5). During washout of the highest concentrations, a significant reduction of the b-wave amplitude to $72.8 \pm 7.7 \%$ was observed, which may be the result of the longer lasting procedure of successive application of increasing tricine concentrations. The lack of b-wave reduction following the application of tricine in the murine retina could be explained by the presence of L-glutamate (L-Glu) in the Ames solution, because L-Glu and other amino acids are known to chelate divalent cations similar to tricine [2].

2.2 Stimulation of transretinal signaling by copper (II) ions in Ca 2.3 competent mice 
Since adding tricine to the perfusion solution had no effect on the ERG b-wave, we concluded that L-Glu from the Ames solution chelated any impurities from the nutrient solution additives, resulting in different signals when compared to recording of the bovine retina [28]. Next, the scotopic full ERG was recorded from six independent freshly isolated retinae either from control or from $\mathrm{Ca}_{\mathrm{v}} 2$.3-deficient mice (first eye only). After 30 min of superfusion with nominally $100 \mathrm{nM} \mathrm{CuCl}_{2}$ the b-wave amplitude was significantly increased by $28.8 \pm 8.2 \%(p=0.024, n=6)$ in $\mathrm{Ca}_{v} 2$.3-competent mouse retinas. This increase in b-wave amplitude remained irreversible during the subsequent washout (Fig. 2A and 2B). No change of the bwave amplitude was observed in the ERG b-wave responses from $\mathrm{Ca}_{\mathrm{v}}$ 2.3-deficient mouse retinae (Fig. $2 \mathrm{C}$ and 2D). The b-wave amplitude following stimulation with $100 \mathrm{nM} \mathrm{CuCl} 2$ was $101.3 \pm 1.9 \%(n=6)$ and was significantly lower $(p=0.019, n=6)$ than in the $\mathrm{Ca}_{v} 2.3$-competent controls (Fig. 3 ).

In a previous study, the isolated bovine retina exhibited a similar sensitivity towards $100 \mathrm{nM} \mathrm{CuCl}_{2}$ as the retina from wild type mice (for details [28]).

Taken together, these results suggest that submicromolar $\mathrm{CuCl}_{2}$ affects transretinal signaling via the $\mathrm{Ca}_{\mathrm{v}} 2.3 \mathrm{VGCC}$ in the wild type murine and probably also in the bovine retina.

\subsection{Multiple effects of kainic acid $(K A)$ in the murine retina}

For the human $\mathrm{Ca}_{\mathrm{v}} 2.3 \mathrm{R}$-type $\mathrm{Ca}^{2+}$ channel, a reciprocal modulation by $\mathrm{Cu}^{2+}$ and kainic acid was found when stably co-expressed with human $b_{3}$-subunit in HEK-293 cells. Moreover, when tricine was used as a surrogate of kainic acid, it produced effects consistent with $\mathrm{Ca}_{\mathrm{v}} 2.3$ channel modulation both in transfected HEK cells and in the isolated bovine retina [28]. In the murine retina, tricine was ineffective in changing transretinal signaling, likely due to the trace metal chelation by glutamate which was present in the Ames medium. We therefore analyzed the effects of direct administration of kainic acid at the same maximal concentration that was used in the heterologous system [28] by adding $27 \mu \mathrm{M}$ kainic acid to the Ames perfusion solution (Fig. 4). It caused a fast and highly significant increase of the ERG b-wave amplitude in retinas from both genotypes (Fig. 4A and 4B). During the $30 \mathrm{~min}$ superfusion period, a fast increase occurred in $\mathrm{Ca}_{\mathrm{v}} 2$.3-competent mice to $297 \pm 44 \%$ of the initial amplitude in equilibrium and in $\mathrm{Ca}_{\mathrm{v}} 2$ 2.3-deficient mice to $249 \pm 13 \%$ within the first 12 min (both increases were highly significant, $\mathrm{p}<$ $0.01, \mathrm{n}=7$ ( $\mathrm{Ca}_{\mathrm{v}} 2$.3-competent mice) and $\mathrm{n}=6$ ( $\mathrm{Ca}_{\mathrm{v}} 2$.3-deficient mice). The b-wave amplitude was still significantly $(p<0.05)$ increased at the end of the KA washing in period in $\mathrm{Ca}_{\mathrm{v}} 2$.3-competent mice $(184 \pm$ $5 \%$ ) and $\mathrm{Ca}_{\mathrm{v}} 2$.3-deficient mice (162 $\left.\pm 19 \%\right)$. In both genotypes, the b-wave amplitude was significantly reduced $(p<0.001)$ after washout of KA (Fig. 4A and 4B) compared to the initial b-wave amplitude. The maximally observed increases during the beginning of KA superfusion did not reach the level of significance, when comparing both genotypes (Fig. 4C). KA does not have a prominent and visible effect as a chelating agent under the conditions for recording murine ERGs, since no reduction of the ERG $b$ wave amplitude was observed. 
The next series of experiments were performed to block the native ionotropic kainate receptors in the murine retina, in order to unmask a potential chelating effect of KA during transretinal signaling. Two antagonists were used to inhibit the stimulatory effect of KA on its receptors (Fig. 5). The high affinity broad spectrum kainate receptor antagonist UBP 301 [29] was used at 10 and $20 \mu \mathrm{M}$ concentration with either 10,5 or only $1 \mu \mathrm{M} \mathrm{KA}$. However, all three concentrations did not prevent the KA-induced increase of the b-wave amplitude (Fig. 5). Using the competitive AMPA / kainate receptor antagonist CNQX (30 $\mu \mathrm{M})$, which also antagonizes NMDA receptors at glycine sites, a reduction to less than $50 \%$ of the initial amplitude was observed. This effect remained unchanged even in the presence of KA (1 $\mu \mathrm{M})$ leading to the conclusion that KA prominently activates ionotropic glutamate receptors in the murine retina. Thus, the chelating effect of KA cannot be visualized in the organotypic preparation of the isolated murine retina.

\section{Discussion}

During transretinal signaling in the vertebrate retina, VGCCs are involved in basal synaptic signal transduction by triggering $\mathrm{Ca}^{2+}$-mediated glutamate release. In the dark, the excitatory neurotransmitter glutamate is tonically released from ribbon synapses and the rate of release is modulated in response to graded changes in the membrane potential contrasting with action potential-driven bursts of release at conventional synapses [30]. Mainly the two L-type VGCC containing the ion conducting subunits $\mathrm{Ca}_{\mathrm{v}} 1.3$ (a1D) and $\mathrm{Ca}_{\mathrm{v}} 1.4(\mathrm{a} 1 \mathrm{~F})$ appear to form the principle voltage-gated $\mathrm{Ca}^{2+}$ influx pathways in rods and cones [31], but also in the cochlear inner hair cells [32]. The importance of both $\mathrm{Ca}_{\mathrm{v}} 1 \mathrm{~L}^{2}$ type $\mathrm{Ca}^{2+}$ channels during sensory signaling gets obvious after its ablation, either by recombinant technologies for $\mathrm{Ca}_{\mathrm{v}} 1.3$, leading to deafness [33] or after native gene loss for $\mathrm{Ca}_{\mathrm{v}} 1.4$ leading to night blindness [34].

Transsynaptic signaling is modulated by GABA and glycine, and by additional neurotransmitters and other signaling molecules like nitric oxide (NO), acetylcholine and dopamine. So far, these synaptic modulation and integration has not yet been fully understood. For the bovine retina, it was postulated that the R-type $\mathrm{Ca}^{2+}$ channel may be involved in this reciprocal inhibition by triggering the release of inhibitory neurotransmitters [13]. As previously demonstrated in our experiments on the murine retina, such an involvement was deduced by recording and calculating the amplitude changes caused by $\mathrm{Ni}^{2+}$ application, a rather complicated indirect determination, [20]. The inhibitory reciprocal modulation by GABA was related to the expression of both, $\mathrm{Ca}_{\mathrm{v}} 2.3$ / pharmacoresistant R-type and $\mathrm{Ca}_{\mathrm{v}} 3.2$ / T-type voltage-gated $\mathrm{Ca}^{2+}$ channels [20], which are both highly sensitive towards toxic $\mathrm{Ni}^{2+}$.

The ten different genes encoding the ion conducting subunits show different sensitivities towards bioavailable trace metal cations $\mathrm{Zn}^{2+}$ and $\mathrm{Cu}^{2+}$ [3]. Both, $\mathrm{Ca}_{\mathrm{v}}$ 2.3- and $\mathrm{Ca}_{\mathrm{v}}$ 3.2-channels are most sensitive towards $\mathrm{Zn}^{2+}$ and $\mathrm{Cu}^{2+}[2,35]$. Therefore, the sensitivity towards $\mathrm{Cu}^{2+}$, the most effective divalent metal cation inhibitor, was investigated first in the isolated and superfused bovine retina [28] and now in the retina of wild type and genetically modified mice lacking the expression of $\mathrm{Ca}_{\mathrm{v}} 2.3$. The present report 
provides further support to the idea that the assumed $\mathrm{R}$-type $\mathrm{Ca}^{2+}$ channel containing $\mathrm{Ca}_{\mathrm{v}} 2.3$ as ion conducting pore is involved in transretinal signaling and modulated by submicromolar $\mathrm{Cu}^{2+}$ concentrations. This concentration mimics the in vivo situation and indicates that $\mathrm{Cu}^{2+}$ and probably also other bioavailable trace metal cations could help to modulate the strength of signal propagated through the retinal network in vivo.

Major differences between the $\mathrm{Cu}^{2+}$ effects on transretinal signaling, which will be discussed, are related to a genotype-related difference. The genotype-dependent stimulation in $\mathrm{Ca}_{\mathrm{v}} 2$.3-competent mice shows that submicromolar $\mathrm{Cu}^{2+}$ mediates its effect clearly via $\mathrm{Ca}_{v} 2.3$, the pharmacoresistant $\mathrm{Ca}^{2+}$ channel, which, in the bovine retina, was thought to trigger GABA-release from amacrine cells onto ON-bipolar neurons. This release of inhibitory neurotransmitters was deduced from the sensitivity of the b-wave to stimulation by $\mathrm{Ni}^{2+}[12,13], \mathrm{Zn}^{2+}[8]$ and $\mathrm{Cu}^{2+}[28]$. For the isolated murine retina expressing $\mathrm{Ca}_{\mathrm{v}} 2.3$, the same concentration of $\mathrm{CuCl}_{2}(100 \mathrm{nM})$ caused a similar effect, namely a significant $30 \%$ increase of the ERG b-wave amplitude, which was not observed in the retinae from $\mathrm{Ca}_{\mathrm{v}} 2$ 2.3-deficient mice.

It should be noted that the bovine retina [10] was isolated and recorded in a different medium than the murine retina [11], although in both cases, the solutions were optimized to achieve a maximal b-wave response, indicative of a "healthy" retina. The major difference between both nutrient solutions is related to the absence (bovine) or presence (murine) of an amino acid cocktail including glutamate, which can chelate submicromolar concentrations of divalent trace metal cations. Therefore, control recordings by chelating $\mathrm{Cu}^{2+}$ after application of tricine failed for the murine retina (present report, Fig. 1) but not for the bovine retina [28]. Attempts to record from the murine retina under conditions previously used for the bovine retina (i.e. with Sickel instead of Ames medium) failed, possibly reflecting the higher metabolic needs of the murine retina.

Another set of experiments was related to the effects of kainic acid, which is routinely used to induce experimental seizures in mice. As this drug is also able to chelate trace metal cations, we tested its effects on transretinal signal transduction in the isolated retina. Kainic acid (KA) probably affects more efficiently the high-affinity binding sites of the classical non-N-methyl-D-aspartate (non-NMDA) ionotropic glutamate receptors, which are expressed in the murine retina [36, 37]. Under the conditions for recording murine ERGs in our setup, KA did not have a prominent and visible effect as a chelating agent, since no reduction of the ERG b-wave amplitude was observed. However, we failed to find any effect on the $\mathrm{Cu}^{2+}$ mediated stimulation, because endogenous kainate receptors could not be blocked completely by KAreceptor antagonists or the antagonists themselves showed pronounced effects on transretinal signal transduction (Fig 5).

\section{Conclusion}

The present report demonstrates that submicromolar concentrations of the physiologically relevant trace metal ion $\mathrm{Cu}^{2+}$ cause an increase of the b-wave amplitude in retinae from wild type but not $\mathrm{Ca}_{\mathrm{v}} 2.3-$ 
deficient mice, suggesting that the effect is mediated by suppression of $\mathrm{Ca}_{\mathrm{v}} 2.3$ channels. Based on previous studies in the bovine retina, $\mathrm{Ca}_{\mathrm{v}} 2$.3-triggered GABA release could activate chloride influx into $\mathrm{ON}$ bipolar cells and thereby reduce the b-wave amplitude [13]. Thus, inhibition of $\mathrm{Ca}_{\mathrm{v}} 2.3$ by $\mathrm{CuCl}_{2}$ may reduce reciprocal inhibition via GABA receptors and would increase the b-wave amplitude, as shown here for the murine retina. Kainic acid did not show any visible effects as a chelator for ions on murine ERG, demanding advanced experimental studies to understand the mechanism more precisely.

\section{Abbreviations}

$\mathrm{Ca}^{2+}$, calcium ions

$\mathrm{Ca}_{v} 2.3$, the ion conducting subunit of the pharmacoresistant voltage-gated calcium channel

CNQX, 7-nitro-2,3-dioxo-1,4-dihydroquinoxaline-6-carbonitrile, a competitive AMPA / kainate receptor antagonist

ERG, electroretinogram

GABA, gamma amino butyric acid

$\mathrm{KA}$, kainic acid

L-type, subfamily of high-voltage gated calcium channels with four members $\left(\mathrm{Ca}_{\mathrm{v}} 1.1\right.$ to $\left.\mathrm{Ca}_{\mathrm{v}} 1.4\right)$

NMDA, N-methyl-D-aspartate

R-type, member of the subfamily $\mathrm{Ca}_{v} 2$ of the high-voltage gated calcium $\left(\mathrm{Ca}_{\mathrm{v}} 2.3\right)$

VGCC, voltage-gated calcium channel

\section{Declarations}

\section{Ethics approval and consent to participate}

All experiments on animal care were approved by the local institutional committee at the University of Cologne and in connection with the government institution, the LANUV (UniKöln_Anzeige§4.17.007).

\section{Consent for publication}

- not applicable -

\section{Availability of data and materials}

All data are available on the local backup computer and will be sent upon request. 


\section{Competing interests}

The authors declare that the research was conducted in the absence of any commercial or financial relationships that could be construed as a potential conflict of interest.

\section{Funding}

This work was financially supported by the Deutsche Forschungsgemeinschaft (DFG, SCHN 387/21-1).

\section{Authors' contributions}

JN, FN, SA, TS, WA and IAS have made substantial contributions to the conception and design of the work. JN, FN, TS and IAS have made substantial contributions to the acquisition, analysis and interpretation of data. WA has made substantial contributions to the creation of new software used in the work. FN, JH, TS, WA and IAS have drafted the work and substantively revised it. All authors have approved the submitted version of the manuscript, tables and figures, and all have agreed both to be personally accountable for the author's own contributions. They ensure that questions related to the accuracy of integrity of any part of the work, even ones in which the author was not personally involved, are appropriately investigated, resolved, and the resolution documented in the literature.

\section{Acknowledgements}

We would like to specially thank Mrs. Renate Clemens for their dedication and hard work.

\section{References}

1. Graham SF, Nasaruddin MB, Carey M, Holscher C, McGuinness B, Kehoe PG, Love S, Passmore P, Elliott CT, Meharg AA, Green BD (2014) Age-associated changes of brain copper, iron, and zinc in Alzheimer's disease and dementia with lewy bodies. J Alzheimers Dis 42: 1407-1413

2. Shcheglovitov A, Vitko I, Lazarenko RM, Orestes P, Todorovic SM, Perez-Reyes E (2012) Molecular and biophysical basis of glutamate and trace metal modulation of voltage-gated $\mathrm{Ca}(\mathrm{v}) 2.3$ calcium channels. J Gen Physiol 139: 219-234

3. Neumaier F, Dibué-Adjei M, Hescheler J, Schneider T (2015) Voltage-gated calcium channels: Determinants of channel function and modulation by inorganic cations. Progress in Neurobiology 129: $1-36$

4. Mathie A, Sutton GL, Clarke CE, Veale EL (2006) Zinc and copper: pharmacological probes and endogenous modulators of neuronal excitability. Pharmacol Ther 111: 567-583

5. Traboulsie A, Chemin J, Chevalier M, Quignard JF, Nargeot J, Lory P (2007) Subunit-specific modulation of T-type calcium channels by zinc. J Physiol 578: 159-171

6. Ma Z, Wong KY, Horrigan FT (2008) An extracellular Cu2+ binding site in the voltage sensor of BK and Shaker potassium channels. J Gen Physiol 131: 483-502 
7. Chappell RL, Anastassov I, Lugo P, Ripps H (2008) Zinc-mediated feedback at the synaptic terminals of vertebrate photoreceptors. Exp Eye Res 87: 394-397

8. Siapich SA, Wrubel H, Albanna W, Alnawaiseh M, Hescheler J, Weiergräber $M$, Lüke $M$, Schneider T (2010) Effect of $\mathrm{ZnCl} 2$ and chelation of zinc ions by N,N-diethyldithiocarbamate (DEDTC) on the ERG b-wave amplitude from the isolated and superfused vertebrate retina. Curr Eye Res 35: 322-334

9. Sickel w (1972) Electrical and metabolic manifestations of receptor and higher-order neuron activity in vertebrate retina. Adv Exp Med Biol 24: 101-118

10. Lüke M, Weiergräber M, Brand C, Siapich SA, Banat M, Hescheler J, Lüke C, Schneider T (2005) The isolated perfused bovine retina - a sensitive tool for pharmacological research on retinal function. Brain Res Brain Res Protoc 16: 27-36

11. Albanna W, Lueke JN, Sjapic V, Kotlair K, Hescheler J, Clusmann H, Sjapic S, Alpdogan S, Schneider T, Schubert GA, Neumaier F (2017) Electroretinographic assessment of inner retinal signaling in the isolated and superfused murine retina. Curr Eye Res 42: 1518-1526

12. Lüke M, Henry M, Lingohr T, Maghsoodian M, Hescheler J, Sickel w, Schneider T (2005) A Ni ${ }^{2+}$ sensitive component of the ERG-b-wave from the isolated bovine retina is related to E-type voltagegated $\mathrm{Ca}^{2+}$ channels. Graefes Arch Clin Exp Ophthalmol 243: 933-941

13. Siapich SA, Banat M, Albanna W, Hescheler J, Lüke M, Schneider T (2009) Antagonists of ionotropic gamma-aminobutyric acid receptors impair the NiCl2-mediated stimulation of the electroretinogramm b-wave amplitude from the isolated superfused vertebrate retina. Acta Ophthalmol 87: 854-865

14. Neumaier F, Akhtar-Schafer I, Luke JN, Dibue-Adjei M, Hescheler J, Schneider T (2018) Reciprocal modulation of Cav 2.3 voltage-gated calcium channels by copper(II) ions and kainic acid. J Neurochem 147: 310-322 DOI 10.1111/jnc.14546

15. Shcheglovitov A, Vitko I, Lazarenko RM, Orestes P, Todorovic SM, Perez-Reyes E (2012) Molecular and biophysical basis of glutamate and trace metal modulation of voltage-gated $\mathrm{Ca}(\mathrm{v}) 2.3$ calcium channels. J Gen Physiol 139: 219-234 DOI 10.1085/jgp.201110699

16. Wang Q, Yu S, Simonyi A, Sun GY, Sun AY (2005) Kainic acid-mediated excitotoxicity as a model for neurodegeneration. Mol Neurobiol 31: 3-16 DOI 10.1385/MN:31:1-3:003

17. Weiergraber M, Henry M, Radhakrishnan K, Hescheler J, Schneider T (2007) Hippocampal seizure resistance and reduced neuronal excitotoxicity in mice lacking the Cav2.3 E/R-type voltage-gated calcium channel. J Neurophysiol 97: 3660-3669 DOI 10.1152/jn.01193.2006

18. Dibue-Adjei M, Kamp MA, Alpdogan S, Tevoufouet EE, Neiss WF, Hescheler J, Schneider T (2017) Cav2.3 (R-Type) Calcium Channels are Critical for Mediating Anticonvulsive and Neuroprotective Properties of Lamotrigine In Vivo. Cell Physiol Biochem 44: 935-947 DOI 10.1159/000485361

19. Albanna W, Banat M, Albanna N, Alnawaiseh M, Siapich SA, Igelmund P, Weiergraber M, Luke M, Schneider T (2009) Longer lasting electroretinographic recordings from the isolated and superfused murine retina. Graefes Arch Clin Exp Ophthalmol 247: 1339-1352 
20. Alnawaiseh M, Albanna W, Chen C-C, Campbell KP, Hescheler J, Lüke M, Schneider T (2011) Two separate $\mathrm{Ni}^{2+}$ sensitive voltage-gated $\mathrm{Ca}^{2+}$ channels modulate transretinal signalling in the isolated murine retina. Acta Ophthalmologica 89: e579-e590

21. Ames A, III, Nesbett FB (1981) In vitro retina as an experimental model of the central nervous system. J Neurochem 37: 867-877

22. Coleman PA, Carras PL, Miller RF (1987) Barium reverses the transretinal potassium gradient of the amphibian retina. Neurosci Lett 80: 61-65 DOI 0304-3940(87)90495-2 [pii]

23. Pereverzev A, Mikhna M, Vajna R, Gissel C, Henry M, Weiergräber M, Hescheler J, Smyth N, Schneider $\mathrm{T}$ (2002) Disturbances in glucose-tolerance, insulin-release and stress-induced hyperglycemia upon disruption of the Cav2.3 (a1E) subunit of voltage-gated Ca2+ channels. Mol Endocrinol 16: 884-895

24. Weiergräber M, Henry M, Krieger A, Kamp MA, Radhakrishnan K, Hescheler J, Schneider T (2006) Altered seizure susceptibility in mice lacking the Cav2.3 E-type $\mathrm{Ca}^{2+}$ channel. Epilepsia 47: 839-850

25. Pereverzev A, Mikhna M, Vajna R, Gissel C, Henry M, Weiergraber M, Hescheler J, Smyth N, Schneider $T$ (2002) Disturbances in glucose-tolerance, insulin-release, and stress-induced hyperglycemia upon disruption of the $\mathrm{Ca}(\mathrm{v}) 2.3$ (alpha 1E) subunit of voltage-gated $\mathrm{Ca}(2+)$ channels. Mol Endocrinol 16: 884-895 DOI 10.1210/mend.16.4.0801

26. Albanna W, Banat M, Albanna N, Alnawaiseh M, Siapich SA, Igelmund P, Weiergraber M, Luke M, Schneider T (2009) Longer lasting electroretinographic recordings from the isolated and superfused murine retina. Graefes Arch Clin Exp Ophthalmol 247: 1339-1352 DOI 10.1007/s00417-009-1119-1

27. Azevedo AW, Rieke F (2011) Experimental protocols alter phototransduction: the implications for retinal processing at visual threshold. J Neurosci 31: 3670-3682 DOI 10.1523/JNEUROSCI.475010.2011

28. Neumaier F, Akhtar-Schafer I, Luke JN, Dibue-Adjei M, Hescheler J, Schneider T (2018) Reciprocal modulation of Cav 2.3 voltage-gated calcium channels by copper(II) ions and kainic acid. J Neurochem 147: 310-322 DOI 10.1111/jnc.14546 [doi]

29. More JC, Nistico R, Dolman NP, Clarke VR, Alt AJ, Ogden AM, Buelens FP, Troop HM, Kelland EE, Pilato F, Bleakman D, Bortolotto ZA, Collingridge GL, Jane DE (2004) Characterisation of UBP296: a novel, potent and selective kainate receptor antagonist. Neuropharmacology 47: 46-64 DOI 10.1016/j.neuropharm.2004.03.005 [doi];S0028390804000668 [pii]

30. Morgans CW (2000) Neurotransmitter release at ribbon synapses in the retina. Immunol Cell Biol 78: 442-446 DOI icb923 [pii];10.1046/j.1440-1711.2000.00923.x [doi]

31. Barnes S, Kelly ME (2002) Calcium channels at the photoreceptor synapse. Adv Exp Med Biol 514: 465-476

32. Joiner ML, Lee A (2015) Voltage-Gated Cav1 Channels in Disorders of Vision and Hearing. Curr Mol Pharmacol 8: 143-148 DOI CMP-EPUB-67168 [pii]

33. Platzer J, Engel J, Schrott-Fischer A, Stephan K, Bova S, Chen H, Zheng H, Striessnig J (2000) Congenital deafness and sinoatrial node dysfunction in mice lacking class $\mathrm{D}$ L-type $\mathrm{Ca}^{2+}$ channels. 
Cell 102: 89-97

34. Bech-Hansen NT, Naylor MJ, Maybaum TA, Pearce WG, Koop B, Fishman GA, Mets M, M.A. M, cott KM (1998) Loss-of-function mutations in a calcium-channel a1-subunit gene in Xp11.23 cause incomplete X-linked congenital stationary night blindness. Nature Genet 19: 264-267

35. Kang HW, Vitko I, Lee SS, Perez-Reyes E, Lee JH (2010) Structural determinants of the high affinity extracellular zinc binding site on Cav3.2 T-type calcium channels. J Biol Chem 285: 3271-3281

36. Yang XL (2004) Characterization of receptors for glutamate and GABA in retinal neurons. Prog Neurobiol 73: 127-150 DOI 10.1016/j.pneurobio.2004.04.002 [doi];S0301008204000577 [pii]

37. Yang J, Nemargut JP, Wang GY (2011) The roles of ionotropic glutamate receptors along the On and Off signaling pathways in the light-adapted mouse retina. Brain Res 1390: 70-79 DOI S00068993(11)00514-2 [pii];10.1016/j.brainres.2011.03.017 [doi]

\section{Table}

Table 1: Comparison of nutrient solutions used for ERG recordings from bovine (Sickel-medium) or murine isolated retina (modified AMES-medium). AMES-medium was modified by increasing the pH slightly to alkaline ( $\mathrm{pH}$ 7.7) and by adding $0.1 \mathrm{mM} \mathrm{BaCl} 2$.

\begin{tabular}{|c|c|c|}
\hline Nutrient & Sickel-medium & modified AMES-medium \\
\hline $\mathrm{NaCl}$ & $120 \mathrm{mM}$ & $120 \mathrm{mM}$ \\
\hline $\mathrm{KCl}$ & $2 \mathrm{mM}$ & $3.1 \mathrm{mM}$ \\
\hline $\mathrm{CaCl}_{2}$ & $0.15 \mathrm{mM}$ & $1.15 \mathrm{mM}$ \\
\hline $\mathrm{MgCl}_{2} / \mathrm{MgSO}_{4} * 7 \mathrm{H}_{2} \mathrm{O}$ & $0.1 \mathrm{mM}$ & - \\
\hline D-glucose & $5 \mathrm{mM}$ & $6 \mathrm{mM}$ \\
\hline $\mathrm{MgSO}_{4}$ & - & $1.24 \mathrm{mM}$ \\
\hline $\mathrm{KH}_{2} \mathrm{PO}_{4}$ & - & $0.5 \mathrm{mM}$ \\
\hline $\mathrm{NaH}_{2} \mathrm{PO}_{4}$ & $1.5 \mathrm{mM}$ & - \\
\hline $\mathrm{Na}_{2} \mathrm{HPO}_{4}$ & $13.5 \mathrm{mM}$ & - \\
\hline \multirow[t]{2}{*}{$\mathrm{NaHCO}_{3}$} & - & $22.6 \mathrm{mM}(\mathrm{pH} 7.4)$ \\
\hline & & $45.3 \mathrm{mM}(\mathrm{pH} 7.7)$ \\
\hline L-glutamine, amino acids, vitamins and other components & - & Sigma-Aldrich Nr. A1420 \\
\hline \multirow[t]{2}{*}{ Equilibration } & Pure oxygen & Carbogen gasing \\
\hline & & containing $5 \%(\mathrm{v} / \mathrm{v})$ of $\mathrm{CO}_{2}$ in $\mathrm{O}_{2}$ \\
\hline pH & 7.8 & $7.4-7.7$ \\
\hline $\mathrm{BaCl}_{2}$ & - & $0.1 \mathrm{mM}$ \\
\hline
\end{tabular}




\section{Wild type; $\mathbf{n}=\mathbf{5}$}

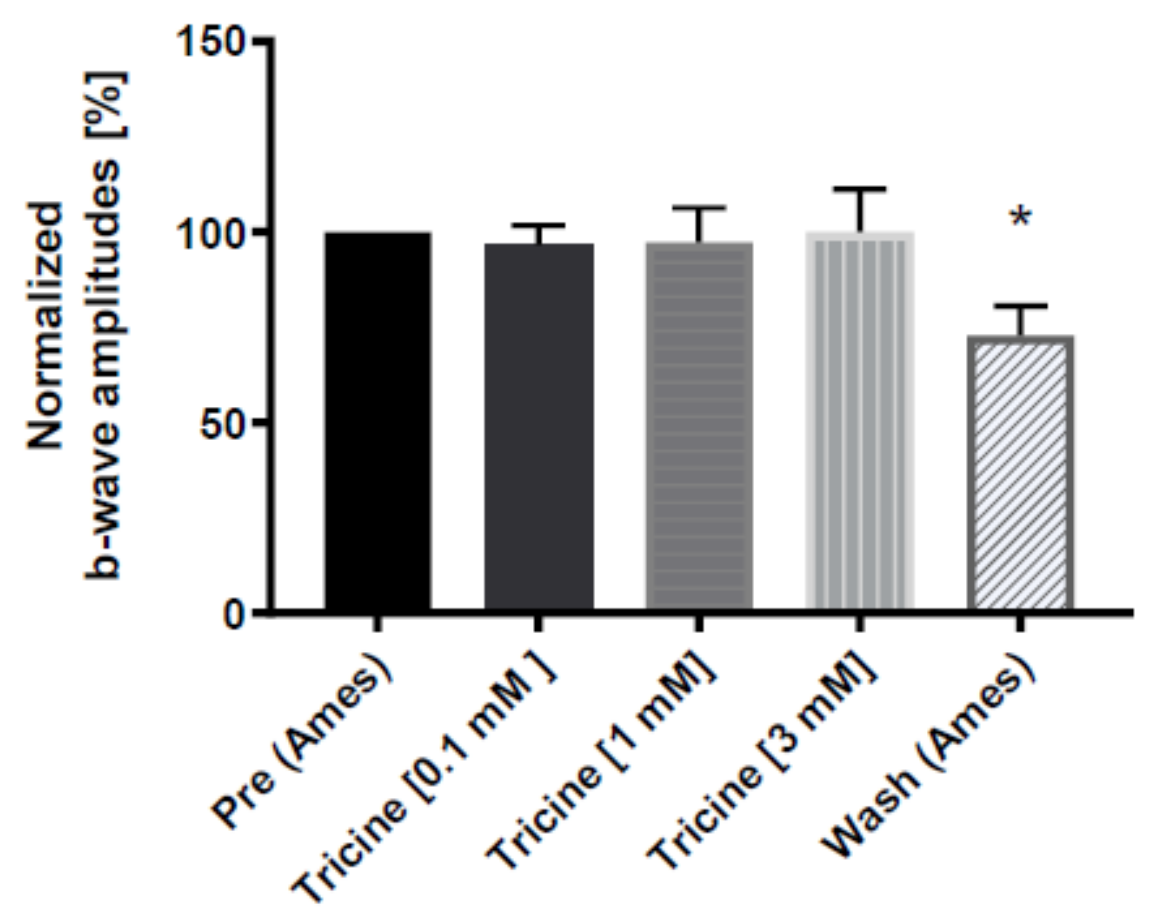

Figure 1

Comparison of the normalized b-wave amplitudes from five isolated retinas ( $n=5$ mice) after successive application of increasing concentrations of tricine and its washout. The initial b-wave amplitude, after reaching the equilibrium in Ames-medium, was set to $100 \%$ (= Pre). Tricine did not affect the ERG b-wave amplitude compared to the initial amplitude in equilibrium ( $0.1 \mathrm{mM}$ tricine: $96.5 \pm 5,2 \% ; 1 \mathrm{mM}: 97.3 \pm$ $9.0 \%$; $3 \mathrm{mM}: 100.1 \pm 11.1 \%$ ). After washout (= Post) the amplitude was significantly reduced to $72.8 \pm$ $7.7 \%$. 
B Wild type; $\mathbf{n}=6$
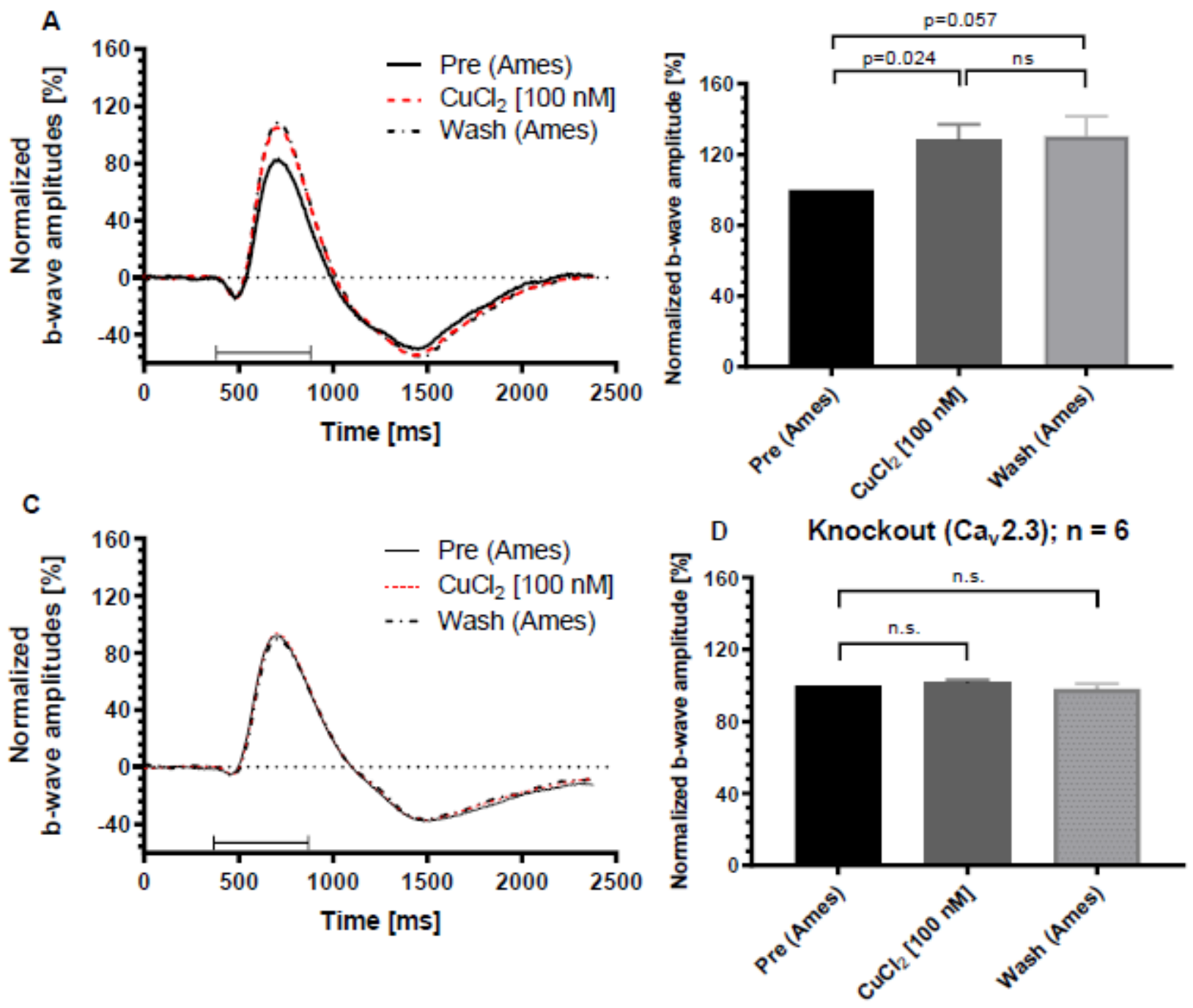

Figure 2

Changes of the b-wave amplitude after application of nominally $100 \mathrm{nM} \mathrm{CuCl} 2$ for control and Cav2.3deficient mice. A. Mean representative ERG traces ( $n=3$ consecutive sweeps) for a single retina from Cav2.3-competent mice before, after 30 min of superfusion with $100 \mathrm{nM} \mathrm{CuCl} 2$ in modified Ames-medium as well as after $30 \mathrm{~min}$ of washout. B. Normalized mean values for retinas ( $n=6$ separate retinas) from Cav2.3-competent mice before and after the superfusion with $100 \mathrm{nM} \mathrm{CuCl} 2$ as well as after $30 \mathrm{~min}$ of washout. C. Mean representative ERG traces ( $n=3$ consecutive sweeps) for a single Cav2.3-deficient retina before and after 30 min of superfusion with $100 \mathrm{nM} \mathrm{CuCl} 2$ in modified Ames-medium as well as after 30 min of washout. Note, that in comparison to the competent mice no change of the b-wave amplitude was observed (all three traces line up together). D. Normalized mean values for retinas ( $n=6$ separate retinas) from Cav2.3-deficient mice before and after the superfusion with $100 \mathrm{nM} \mathrm{CuCl} 2$ as well as after 30 min of washout. Note, that in comparison to the Cav2.3(+|+) mice no significant change of the b-wave amplitude was observed. 
A Murine retina

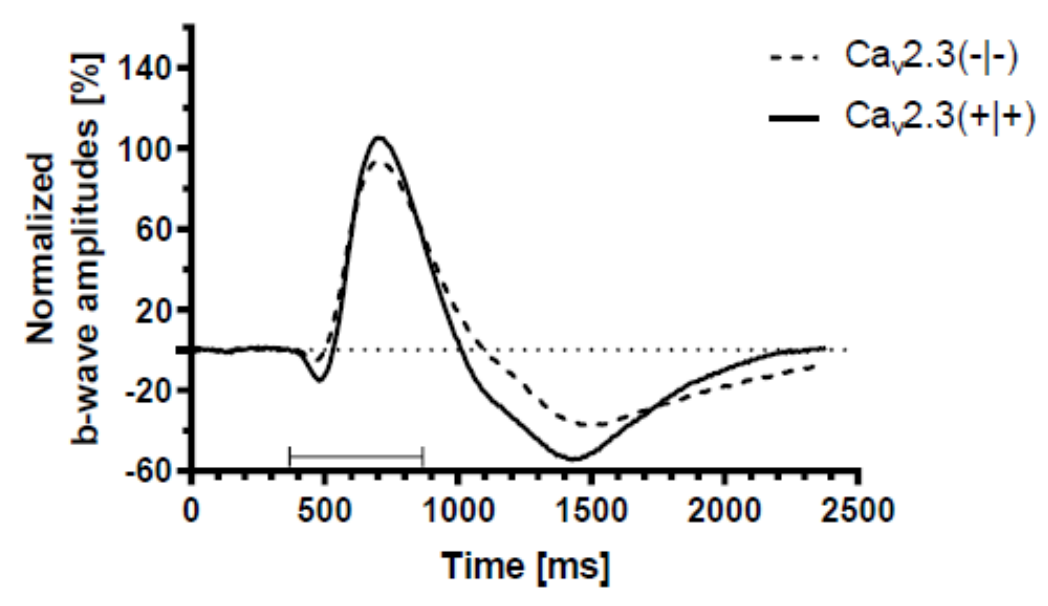

B

Wild type vs. $\mathrm{KO}\left(\mathrm{Ca}_{\mathrm{v}} 2.3-\mathrm{-}-\mathrm{-}\right) ; \mathrm{n}=6$

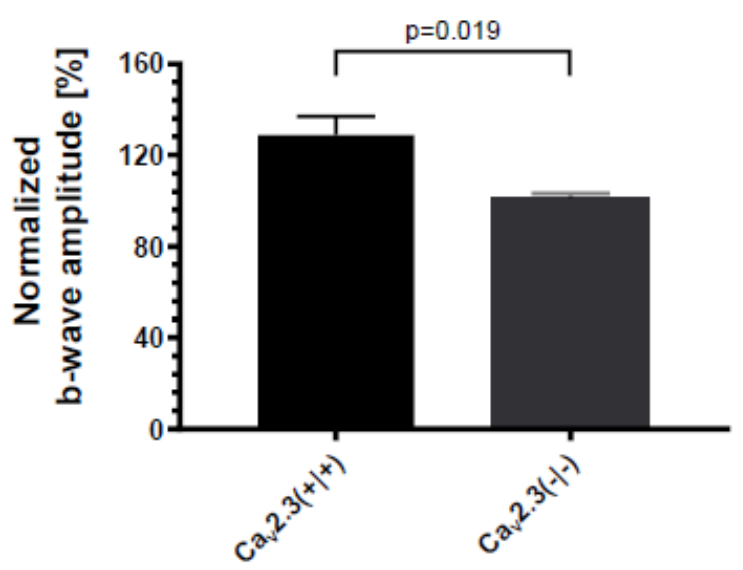

Figure 3

Comparison of the ERG b-wave amplitudes and shape of the ERG traces from both murine genotypes. A. Representative ERG tracers from wild type and Cav2.3-deficient mice, 30 min after superfusion with 100 $\mathrm{nM} \mathrm{CuCl}$ 2. B. After $30 \mathrm{~min}$ of superfusion with $100 \mathrm{nM} \mathrm{CuCl} 2$ the b-wave amplitude is significantly increased to $129 \% \pm 8 \%(n=6)$ for the retina from wild type but not from Cav2.3-deficient mice $(101 \%$ $+/-2 \%, n=6)$. Note, the shape of the ERG traces from both genotypes differ substantially shortly after the end of the triggering light flash. 


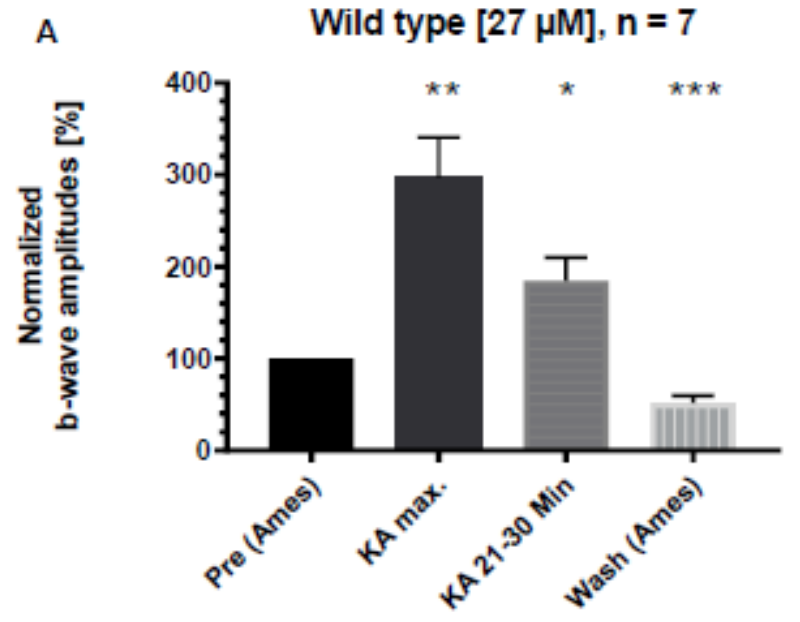

Wild type [27 $\mu \mathrm{M}], \mathrm{n}=7$

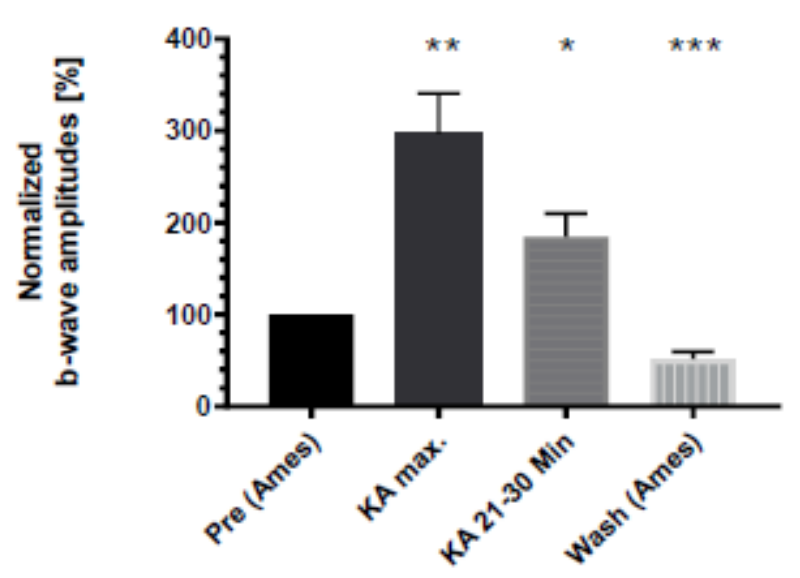

B

$\mathrm{KO}\left(\mathrm{Ca}_{\mathrm{v}} 2.3-\mathrm{I}-\right)[27 \mu \mathrm{M}], \mathrm{n}=6$

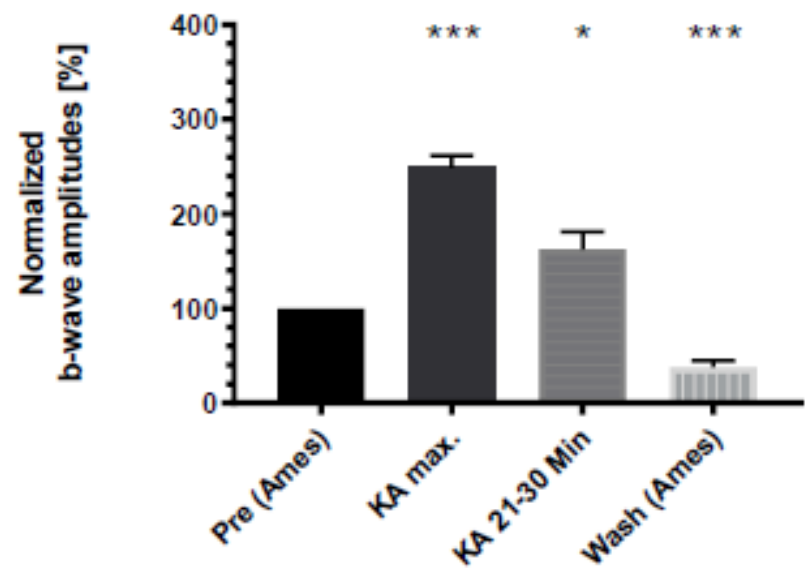

C

Wild type vs. KO ( $\left.\mathrm{Ca}_{\mathrm{v}} 2.3-\mathrm{l}-\right)$
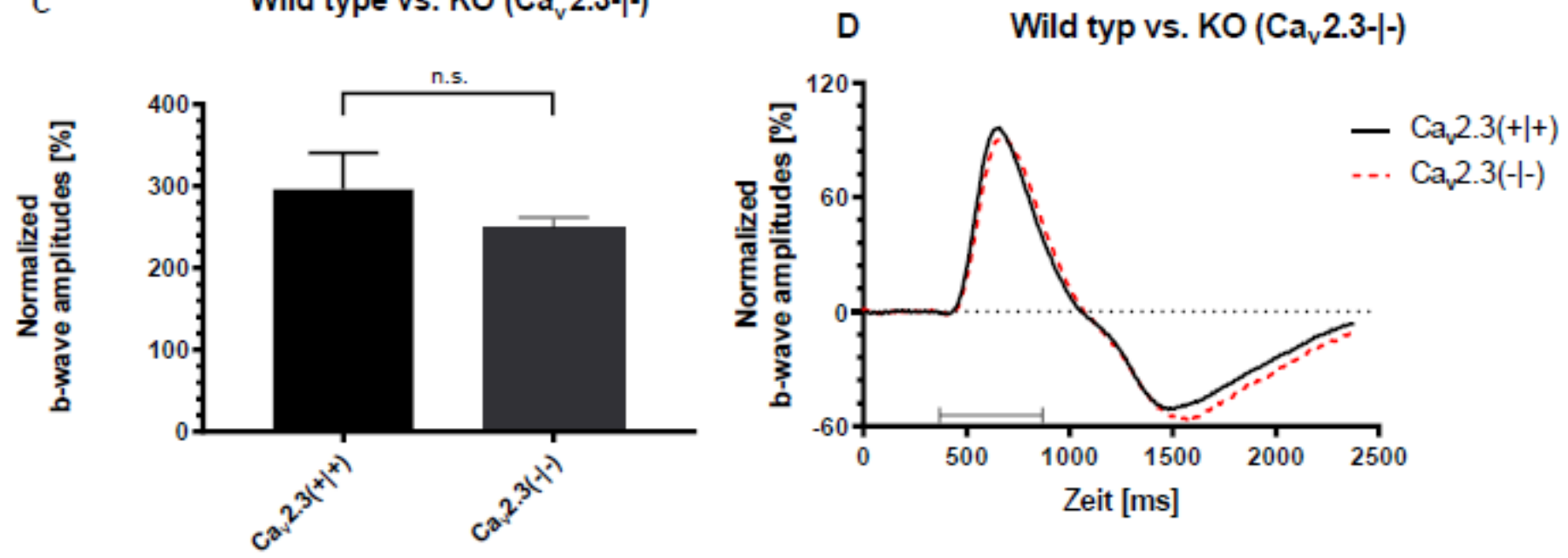

Figure 4

Effect of kainate superfusion on the ERG b-wave amplitudes from both genotypes. After reaching the equilibrium of a maximum b-wave amplitude without kainate (KA), the nutrient solution was completed with $27 \mu \mathrm{M}$ KA causing a transient increase of the b-wave amplitude. For each genotype, the initial amplitude ("Ames") was plotted as 100 \%. The subsequent maximum amplitude ("KA max.") and the amplitude at the end of the 30 min superfusion period ("KA 21/30 Min.") was plotted as relative increase, respectively. During washout the amplitude decreased beyond the initial equilibrium value. A. Normalized amplitudes of the retinas from Cav2.3/competent mice $(n=7)$. B. Normalized amplitudes of the retinas from Cav2.3-deficient mice $(n=6)$. C. Comparison of the maximum values from panel $A$ and $B$ for both genotypes. The maximum increase was not significantly different between both genotypes. D. Overlay of the mean traces for wild type and Cav2.3-deficient mice. 


\section{Kainate receptor antagonists}

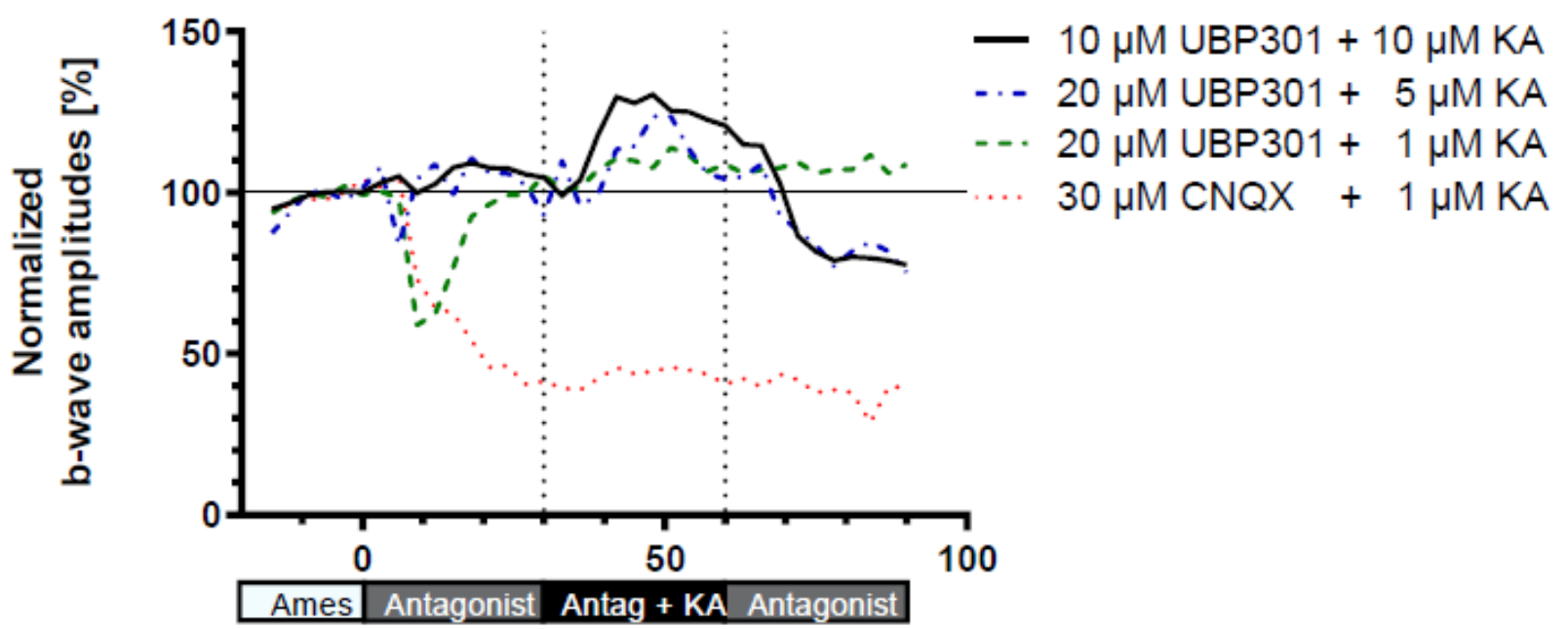

Time [min]

\section{Figure 5}

Effect of KA-receptor antagonists on the KA-mediated increase of the ERG b-wave amplitudes from Cav2.3-competent mice. Normalized amplitudes were plotted under the conditions as indicated. KA was added in the presence of the KA-receptor antagonists. Note, only under $30 \mu \mathrm{M} C N Q X$ the amplitude increase was completely prevented.

\section{Supplementary Files}

This is a list of supplementary files associated with this preprint. Click to download.

- renamed670ce.pdf 